Article

\title{
Synergy of Parameters Determining the Optimal Properties of Coal as a Natural Sorbent
}

\author{
Katarzyna Godyń ${ }^{1}\left(\mathbb{D}\right.$, Barbara Dutka $^{1}$, Monika Chuchro ${ }^{2}\left(\mathbb{D}\right.$ and Mariusz Młynarczuk ${ }^{2, *}$ (C) \\ 1 The Strata Mechanics Research Institute of the Polish Academy of Sciences, Reymonta 27, \\ 30-059 Kraków, Poland; godyn@img-pan.krakow.pl (K.G.); dutka@img-pan.krakow.pl (B.D.) \\ 2 Faculty of Geology, Geophysics and Environmental Protection, AGH University of Science and Technology; \\ al. Mickiewicza 30, 30-059 Kraków, Poland; chuchro@geol.agh.edu.pl \\ * Correspondence: mlynar@agh.edu.pl
}

Received: 20 March 2020; Accepted: 12 April 2020; Published: 16 April 2020

\begin{abstract}
Selection of the optimal properties of coal as a natural sorbent, both as a sample collected from a seam or of the coal seam itself, requires various parameters to be determined and may not be based on the knowledge of metamorphism degree only. In order to improve the predictions of sorption capacity and the kinetics, analyses of correlation and multiple regression based on the results of laboratory studies were performed for 15 coal samples with various coal rank. The maximum vitrinite reflectance $\left(R_{0}\right)$ for low-rank coals was $0.78-0.85 \%$, and $0.98-1.15 \%$ and $1.85-2.03 \%$ for medium- and high-rank coals, respectively. Coal samples were subjected to technical and petrographic analysis. The gravimetric method was used to perform sorption tests using methane, in order to determine the sorption capacity and the effective diffusion coefficient for each of the coals. Pycnometric methods were used to determine the textural parameters of coals, such as the percentage porosity and specific pore volume. The studies were further supplemented with an evaluation of the mechanical properties of the coals, Vickers micro-hardness, and elastic modulus. This work shows that the statistical multiple regression method enables a computational model including the selected petrophysical parameters displaying synergy with the specific sorption property-capacity or kinetics-to be created. The results showed the usefulness of this analysis in providing improved predictions of the optimal sorption properties of coal as a natural sorbent.
\end{abstract}

Keywords: coal; methane; coal petrography; sorption capacity; multiple regression

\section{Introduction}

Coal is a natural, microporous material with an extended pore structure, surrounded by cracks and splitting planes. This material shows high sorption affinity to gases genetically related to coal deposits: carbon dioxide and methane [1]. Even though $\mathrm{CO}_{2}$ is naturally present in nature, its excessive emission into the environment as a result of anthropogenic activity places it among gases with the strongest influence on climate warming. Because of the significant emissions into the environment, generated mainly by the power sector, field studies and tests aimed at sequestration of $\mathrm{CO}_{2}$ in geological formations are undertaken [2]. Processes included in carbon capture and storage (CCS) are still considered in the case of yet unused coal deposits [3]. The enhanced coal bed methane recovery process (ECBM), despite many difficulties, is an attractive method cancelling out the adverse effects of $\mathrm{CO}_{2}$ because of the additional benefit in the form of obtained valuable energy source. Further, as ecological fuel, coalbed methane has been used over the years in North America and Australia, as well as in other countries. Coal has recently been considered as a low-cost sorbent, selective towards $\mathrm{CO}_{2}$, especially at low pressures [4], and still, all topics related to this fossil fuel are extremely desirable from the practical point of view in this context [5-7]. 
Selection of coal with optimal properties is a complex and time-consuming process. Comprehensive characteristics of the coal material, including identification of the sorbent structure and its quality parameters, play an important role in this process. Various groups of parameters are determined, including technical, petrographic, textural, sorption, and strength. These parameters vary with changes of the metamorphism degree of the coal and may be dictated by different geneses and origins [8].

The sorption capacity of coal and the effective diffusion coefficient of gas in the coal are used in quantitative determination of sorption properties, accumulative and kinetic, respectively $[9,10]$. These parameters are determined based on constant pressure sorption test under specified pressure and temperature [11]. Most researchers claim that the metamorphism degree of the organic substance in coal determines its sorption properties [12-18]. However, the discrepancies of results of experimental studies show that using the coal rank as the only factor evaluating the sorption capacity of coal is a controversial approach [9,19]. Additionally, the petrographic composition of coal [20-22], the porous structure [23], or the tectonic disturbances affecting the structural and textural features of the coal seam [24] disturb the clear picture of the relationships described in the literature. It is also known that various petrophysical parameters of coal may have different influences on the sorption properties of coal, and the impact of one of the parameters may limit the influence of another [25]. It is thus difficult to be sure that knowing only the degree of metamorphism will be sufficient to predict (reproduce) other sorbent properties. This may be possible using multiple regression, performed on the results of studies on coal parameters [26]. Multiple analysis enables the so-called synergistic effect to be shown, involving the interaction of two or more parameters, enabling a better effect of the combined interaction to be achieved in comparison with the effects of individual factors. This statistical method may be an optimal tool of coal selection as a sorbent for potential applications.

The objective of this work was to attempt to use multiple analysis of the results of laboratory studies performed on coals with various rank. We expected to find trends in the influence of individual coal parameters on the sorption capacity of coal towards methane and the effective diffusion coefficient of methane in coal during this work. The use of multiple analysis enabled us to study the usefulness of the synergistic effect in understanding the variability of the specific sorption property of coal (capacity or kinetics) as a function of rank.

\section{Materials and Methods}

\subsection{Materials}

The authors prepared 15 coal samples for the study, obtained from the Polish and the Czech part of the Upper Silesian Coal Basin (USCB) (Figure 1).

The studied samples included three groups with different metamorphism degree and were labelled as follows:

- Low-rank coal samples: $35,97,141,143$, and 148 with $R_{0}$ in the range of $0.78-0.85 \%(0.82 \%)$;

- Medium-rank coal samples: 227/2, 227/6, 227/9, 227/10, and 227/22 with $R_{0}$ in the range of $0.98-1.15 \%(1.08 \%)$;

- High-rank coal samples: $4006,4030,4031,4032$, and 4033 with $R_{0}$ in the range of $1.85-2.03 \%(1.94 \%)$. 


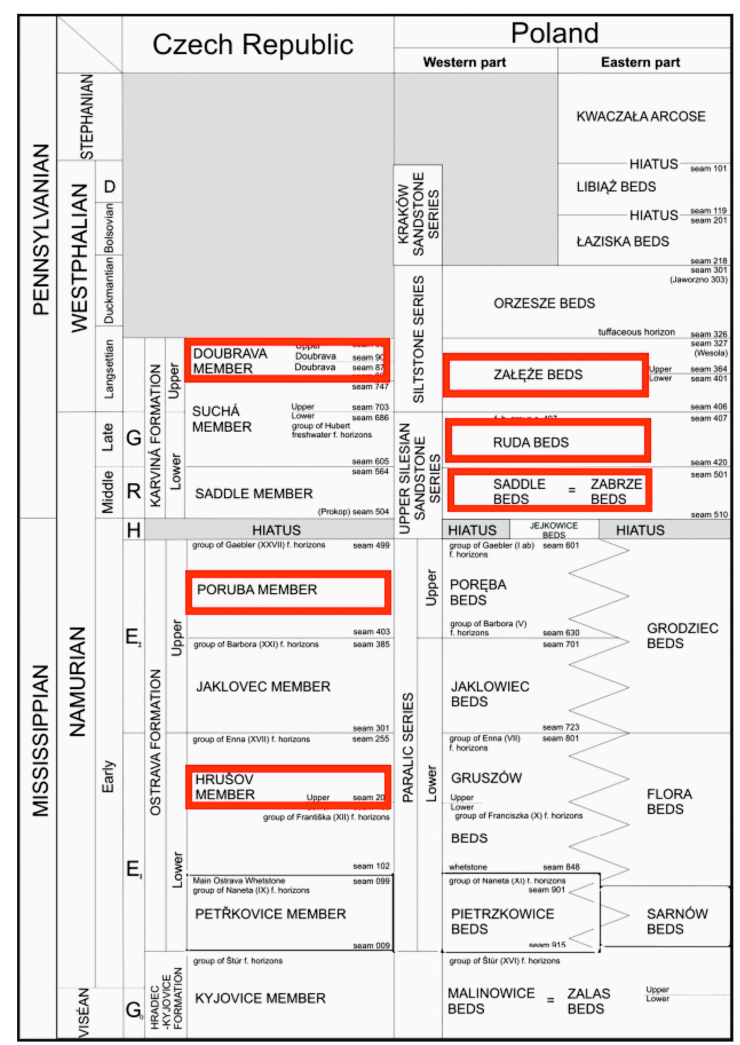

Figure 1. Lithostratigraphic division of the Polish and Czech parts of the Upper Silesian Coal Basin, according to [27], modified by [28] and [29] (Polish part), and [30] modified by [31] and [32] (Czech part). Modified. In red frames, lithostratigraphic formations from which the samples were taken for research are shown.

\subsection{Methodology}

\subsubsection{Technical Analysis}

Technical analysis of coals was performed, including determination of the content of volatile matter and of ash. The gravimetric method was used, including procedures provided in the standards related to tests of solid fuels and coal $[33,34]$. Samples intended for testing were pre-dried at $105^{\circ} \mathrm{C}$. The analysis was supplemented by measurements of absolute and apparent density of coals, as described below.

\subsubsection{Texture Studies Using Densimetric Methods}

The evaluation of porous spaces in coal samples was performed using AccuPyc 1340 (helium) and GeoPyc 1360 (quasi-liquid) pycnometers made by Micromeritics, USA. Pycnometric measurements enabled estimation and comparison of texture properties, such as specific pore volume $V_{p}$ and sample percentage porosity $\varepsilon$. The measurements were performed at a constant temperature on coal samples dried at $80{ }^{\circ} \mathrm{C}$. Percentage porosity $\varepsilon$ and specific pore volume $V_{p}$ were determined according to the following formula:

$$
\varepsilon=100\left(1-\frac{\rho_{p}}{\rho_{r}}\right)
$$

and

$$
V_{p}=\frac{1}{\rho_{p}}-\frac{1}{\rho_{r}}
$$

where

$\rho_{p}$-apparent density, $\mathrm{g} / \mathrm{cm}^{3}$;

$\rho_{r}$-absolute density, $\mathrm{g} / \mathrm{cm}^{3}$. 


\subsubsection{Petrographic Analyses}

Microscopic studies were performed on granular polished sections according to the recommendations provided in $[35,36]$. An AXIOPLAN polarization microscope by ZEISS and a computer operated mechanical XYZ table were used in the petrographic analyses. The analysis of coal macerals is one of the basic analyses carried out manually [37], automatically [38], or supported by artificial intelligence methods $[39,40]$. This work is based on traditional manual methods. The analyses were performed using white, reflected light with oil immersion, at $500 \times$ magnification. Point-type quantitative analysis was performed for 1500 measurement points in order to determine the level of petrographic coal ingredients (main maceral groups and mineral substances). The average reflectance $\left(R_{0}\right)$ was also measured for each of the coals, using contamination- and inclusion-free parts of a maceral from the vitrinite group-colotelinite [41]. An Olympus BX50 polarization microscope was used in reflectance measurements, at 400× magnification. The polished sections were analysed in monochromatic light, using oil immersion. The results were obtained using an image analysis system "LUCIA Vitrinite" [42].

\subsubsection{Sorption Studies Using Methane}

Sorption measurements were performed using the IGA-001 gravimetric sorption analyser made by Hiden Isochema, UK. Coal samples with grain size of $0.16 \div 0.25 \mathrm{~mm}$ were used in the studies, after outgassing the sample at $80^{\circ} \mathrm{C}$ for $10 \mathrm{~h}\left(p=10^{-6}\right.$ mbar). Methane sorption isotherms were determined for coals at $20^{\circ} \mathrm{C}$ following determination of the sorption capacity at atmospheric pressure of 1 bar $\left(a_{1}\right), 3$ bar, and 10 bar. Thus, the maximum value of sorption capacity $\left(a_{m}\right)$ was obtained after fitting the Langmuir Equation [43]:

$$
\frac{a}{a_{m}}(p, T)=\frac{b p}{1+b p}
$$

where $a$-methane adsorbed at pressure $\mathrm{p}, \mathrm{cm}^{3} \mathrm{CH}_{4} / \mathrm{g} ; \mathrm{p}$-equilibrium pressure of methane, bar; $T$-temperature, ${ }^{\circ} \mathrm{C} ; a_{m}$-the maximum sorption capacity at $p$ approaching $\infty, \mathrm{cm}^{3} \mathrm{CH}_{4} / \mathrm{g}$; and $b$-Langmuir constant, bar $^{-1}$.

The results were recalculated to standard conditions (STP) and to dry-ash-free basis.

The effective methane diffusion coefficient of methane in coal $\left(D_{e}\right)$ was determined on the basis of the solution of a unipore diffusion model in a grain coal sample [44] and the Timofejew formula [45]:

$$
D_{e}=\frac{0.308 R_{z}^{2}}{\pi^{2} t_{0.5}}
$$

where $D_{e}$-effective diffusion coefficient, $\mathrm{cm}^{2} / \mathrm{s} ; t_{0.5}$ 一the half-time of the sorption process, $\mathrm{s}$; and $R_{z}$ 一the equivalent radius, $\mathrm{cm}$.

\subsubsection{Strength Studies in the Micro Scale}

A micro hardness tester CSM Instruments device was used in micro-hardness analyses, including a conical Vickers indenter made of diamond, an XY table, and the microscope part, additionally provided with image analysis software. After each measurement, the computer recorded the experimental parameters and the attached software enabled processing of the obtained results. This work included several measurements for each tested sample. The load used in coal analysis was $0.5 \mathrm{~N}$. For image analysis, Nikon NIS Elements software was used.

The following parameters were analysed:

- Vickers micro-hardness $\left(H_{v}\right)$, calculated according to the following formula:

$$
H_{v}=\frac{F_{\max }}{9.81 * A_{c}\left(h_{c}\right)}
$$


where $F_{\max }-$ maximum force, $\mathrm{N} ; h_{c}$-indentation depth, $\mu \mathrm{m} ; A_{c}$-surface area of the formed imprint, $\mu \mathrm{m}^{2}$.

- $\quad$ standard elastic modulus $\left(E_{I T}\right)$ calculated according to the Power Law Method described by [46] after [47]:

$$
E_{I T}=\frac{1-v_{s}^{2}}{\frac{1}{E_{r}}-\frac{1-v_{i}^{2}}{E_{i}}}
$$

where $E_{i}$ - elastic modulus of the indenter (constant), (1141 GPa); $v_{i}$-Poisson' ratio of the indenter, (0.07); $E_{r}$-reduced modulus of the indentation contact; $v_{s}$-Poisson' ratio of the sample (user's selection).

- the rate and nature of cracks and other damage caused by the Vickers indenter being pressed into the analysed material. This parameter enabled us to determine the sample behaviour under the used force and how it breaks or deforms, among others.

\subsubsection{Statistical Analysis Methods}

The statistical analysis was performed for 17 variables comprising the results of measurements of the coal samples different parameters: technical (4), petrographic (6), sorption (3), strength (2), and texture (2), describing the coal-methane system. They were intended to be used in the analysis of the relationship between the values of various petrophysical parameters of coal (one or multiple) and the value of the sorption parameter- the capacity $a_{1}, a_{m}$, or the kinetic parameter $D_{e}$, respectively.

The existence of linear relationships between the variables was estimated using Pearson's correlation coefficient $(\mathrm{R})$ and a significance test of the obtained results; the existence of non-linear relationships was also determined using the Spearman's rank correlation method [48]. The existence of functional relationships between variables was also evaluated, together with the ability to predict the sorption parameters using other variables, using the least squares multiple regression method $[48,49]$.

Models taking into account the non-linear relationship between sorption parameters and the explaining variables were also prepared. The MARSpline model and neuron network with a multiple layer perceptron with one layer of hidden neurons were used for this purpose [50].

\section{Results}

\subsection{General Characteristics of Coals}

The results obtained during laboratory tests are presented in Table 1 . The tested coals differed in their volatile matter content $\left(12.80 \% \leq V^{\text {daf }} \leq 40.97 \%\right)$ and ash content $\left(4.99 \% \leq A^{a} \leq 21.28 \%\right)$. The absolute density of the tested coals varied between $1.324 \mathrm{~g} / \mathrm{cm}^{3}$ and $1.495 \mathrm{~g} / \mathrm{cm}^{3}$ (Table 1). The highly metamorphized coal 4032 was characterised by the highest porosity among the studied coal samples, at $\varepsilon=6.6 \%$, with absolute pore volume $V_{p}=0.051 \mathrm{~cm}^{3} / \mathrm{g}$. Medium-rank coal samples, $227 / 9$ and $227 / 22$, were characterised by the lowest porosity $-3.4 \%$ and $3.8 \%$, respectively. These coals were also characterised by the smallest pore ratio of approximately $V_{p}=0.03 \mathrm{~cm}^{3} / \mathrm{g}$. 
Table 1. Results of technical, petrographic, sorption, strength, and texture tests of the studied coal samples.

\begin{tabular}{|c|c|c|c|c|c|c|c|c|c|c|c|c|c|c|c|c|c|c|}
\hline & \multirow[b]{2}{*}{ Sample } & \multicolumn{4}{|c|}{ Technical Parameters } & \multicolumn{6}{|c|}{ Petrographic Parameters } & \multicolumn{3}{|c|}{ Sorption Parameters } & \multicolumn{2}{|c|}{ Strength Param. } & \multicolumn{2}{|c|}{$\begin{array}{l}\text { Textural } \\
\text { Param. }\end{array}$} \\
\hline & & $\begin{array}{c}\rho_{\mathrm{r}} \\
{\left[\mathrm{g} / \mathrm{cm}^{3}\right]}\end{array}$ & $\begin{array}{c}\rho_{\mathrm{p}} \\
{\left[\mathrm{g} / \mathrm{cm}^{3}\right]}\end{array}$ & $\begin{array}{l}V^{\text {daf }} \\
{[\%]}\end{array}$ & $\begin{array}{l}\mathrm{A}^{\mathrm{a}} \\
{[\%]}\end{array}$ & $\begin{array}{c}\mathbf{R}_{0} \\
{[\%]}\end{array}$ & $\begin{array}{c}\mathrm{Vt}^{\mathrm{mmmf}} \\
{[\%]}\end{array}$ & $\begin{array}{c}\mathrm{I}^{\mathrm{mmf}} \\
{[\%]}\end{array}$ & $\begin{array}{c}\mathrm{L}^{\mathrm{mmf}} \\
{[\%]}\end{array}$ & $\begin{array}{c}(\mathrm{Vt}+\mathrm{L})^{\mathrm{mmf}} \\
{[\%]}\end{array}$ & $\begin{array}{c}\mathbf{M} \\
{[\%]}\end{array}$ & $\begin{array}{c}a_{m} \\
{\left[\mathrm{~cm}^{3} / g\right]}\end{array}$ & $\begin{array}{c}a_{1} \\
{\left[\mathrm{~cm}^{3} / g\right.}\end{array}$ & $\mathrm{D}_{\mathrm{e}}\left[\mathrm{cm}^{2} / \mathrm{s}\right]$ & $\begin{array}{c}\mathrm{E}_{\mathrm{IT}} \\
{[\mathrm{GPa}]}\end{array}$ & $\begin{array}{c}\mathbf{H}_{\mathbf{v}} \\
{\left[\mathrm{N} / \mathrm{mm}^{2}\right]}\end{array}$ & $\varepsilon[\%]$ & $\begin{array}{c}V_{p} \\
{\left[\mathrm{~cm}^{3} / g\right]}\end{array}$ \\
\hline 35 & \multirow{5}{*}{$\begin{array}{c}\text { low-rank } \\
\text { coals }\end{array}$} & 1.395 & 1.333 & 36.45 & 10.54 & 0.852 & 76.71 & 16.44 & 6.84 & 83.56 & 9.13 & 17.19 & 2.47 & $4.18 \times 10^{-10}$ & 5.872 & 72.39 & 4.5 & 0.034 \\
\hline 97 & & 1.429 & 1.371 & 40.97 & 14.58 & 0.784 & 85.08 & 4.76 & 10.15 & 95.24 & 14.72 & 17.04 & 2.40 & $4.99 \times 10^{-10}$ & 5.547 & 63.54 & 4.0 & 0.030 \\
\hline 141 & & 1.495 & 1.425 & 34.51 & 21.28 & 0.845 & 47.23 & 39.44 & 13.33 & 60.56 & 13.04 & 14.25 & 1.94 & $8.90 \times 10^{-10}$ & 5.731 & 70.83 & 4.7 & 0.033 \\
\hline 143 & & 1.399 & 1.336 & 40.16 & 7.22 & 0.848 & 88.03 & 8.85 & 3.12 & 91.15 & 13.12 & 10.78 & 1.18 & $4.46 \times 10^{-10}$ & 6.177 & 68.15 & 4.5 & 0.034 \\
\hline 148 & & 1.361 & 1.304 & 36.61 & 4.99 & 0.793 & 68.82 & 17.81 & 13.36 & 82.19 & 1.98 & 14.96 & 1.87 & $4.42 \times 10^{-10}$ & 6.258 & 71.35 & 4.2 & 0.032 \\
\hline $227 / 2$ & \multirow{5}{*}{$\begin{array}{l}\text { medium-rank } \\
\text { coals }\end{array}$} & 1.338 & 1.280 & 24.78 & 6 & 0.977 & 72.73 & 21.27 & 6.00 & 78.73 & 0.74 & 19.32 & 3.89 & $9.77 \times 10^{-10}$ & 5.697 & 54.33 & 4.3 & 0.034 \\
\hline $227 / 6$ & & 1.373 & 1.296 & 23.25 & 6.31 & 1.108 & 76.12 & 18.50 & 5.38 & 81.50 & 0.39 & 16.29 & 2.58 & $6.83 \times 10^{-10}$ & 6.151 & 61.75 & 5.6 & 0.043 \\
\hline $227 / 22$ & & 1.326 & 1.276 & 21.44 & 8.76 & 1.153 & 43.39 & 53.28 & 3.33 & 46.72 & 0.79 & 15.94 & 2.83 & $7.05 \times 10^{-10}$ & 5.980 & 60.39 & 3.8 & 0.030 \\
\hline $227 / 9$ & & 1.344 & 1.298 & 20.79 & 7.54 & 1.098 & 71.09 & 23.80 & 5.11 & 76.20 & 2.56 & 18.46 & 3.31 & $5.75 \times 10^{-10}$ & 6.052 & 62.20 & 3.4 & 0.026 \\
\hline $227 / 10$ & & 1.324 & 1.255 & 20.2 & 5.56 & 1.071 & 87.55 & 9.78 & 2.67 & 90.22 & 3.43 & 16.42 & 2.72 & $4.00 \times 10^{-10}$ & 5.948 & 53.86 & 5.2 & 0.041 \\
\hline 4006 & \multirow{5}{*}{$\begin{array}{l}\text { high-rank } \\
\text { coals }\end{array}$} & 1.403 & 1.314 & 13.62 & 7.54 & 1.94 & 91.29 & 8.71 & 0 & 91.29 & 3.11 & 23.49 & 2.86 & $1.13 \times 10^{-10}$ & 6.220 & 61.22 & 6.4 & 0.048 \\
\hline 4033 & & 1.378 & 1.295 & 13.91 & 8.83 & 1.87 & 85.51 & 14.49 & 0 & 85.51 & 0 & 24.60 & 3.23 & $3.46 \times 10^{-10}$ & 5.750 & 65.00 & 6.0 & 0.047 \\
\hline 4031 & & 1.387 & 1.301 & 12.8 & 6.87 & 2.03 & 78.60 & 21.40 & 0 & 78.60 & 3.75 & 24.62 & 4.31 & $1.7 \times 10^{-10}$ & 5.157 & 50.54 & 6.2 & 0.048 \\
\hline 4032 & & 1.406 & 1.313 & 13.51 & 9.02 & 2.01 & 88.18 & 11.82 & 0 & 88.18 & 2.62 & 23.94 & 4.25 & $2.26 \times 10^{-10}$ & 5.553 & 49.69 & 6.6 & 0.051 \\
\hline 4030 & & 1.408 & 1.327 & 14.26 & 17.14 & 1.85 & 82.43 & 17.57 & 0 & 82.43 & 0.45 & 25.85 & 3.74 & $1.13 \times 10^{-10}$ & 5.665 & 59.13 & 5.7 & 0.043 \\
\hline
\end{tabular}

$\rho_{r}$-absolute density, $\rho_{p}$-apparent density, $V^{\text {daf }}$ —volatile matter yield, daf-dry-ash-free basis, $A^{d}$ —ash yield, $d$-dry basis, $R_{0}$ —vitrinite reflectance, $V t^{m m f}$-vitrinite content, $I^{m m f}$ —inertinite content, $L^{m m f}$-liptinite content, $\left(V_{t}+L\right)^{m m f}$ —sum of vitrinite and liptinite, $M$-mineral matter content, $m m f$-mineral matter-free, $a_{m}$-maximum sorption capacity for methane, $a_{1}$ - sorption capacity at $1 \mathrm{bar}, D_{e}$-effective diffusion coefficient of methane, $E_{I T}$-elastic modulus, $H_{v}$-Vickers microhardness, $\varepsilon$-porosity, $V_{p}$-total pore volume. 


\subsection{Results of Petrographic Analyses}

Measured reflectance encompassed the characteristic values of medium-rank hard coal—types A, $\mathrm{B}$, and C according the UN-ECE classification [51]. Thus, for the purpose of the study, the samples were divided into low-, medium-, and high-rank coals. Depending on the metamorphism degree, the coal is characterised by different optical characteristics, clearly visible under a microscopic, mainly as the shades of grey of individual maceral groups (Figure 2a-f). The darkest shade of grey is present in low-rank coals (Figure 2a,b), while highly metamorphized coals are the lightest (Figure 2e,f). Liptinite group macerals in highly metamorphized coals are not visible under the microscope (Figure $2 \mathrm{e}, \mathrm{f})$. This effect is caused by the second coalification jump $\left(R_{0} \sim 1.3-1.4 \%\right)$, during which the microscopic properties of liptinite changed [52]. Regardless of the metamorphism degree, almost all of the analysed coal samples showed vitrinite as the dominant maceral; only the 227/22 sample showed the domination of inertinite group macerals (53.28 \%) over vitrinite (43.39\%) (Table 1 , Figure 3). Liptinite group macerals are the most abundant in low-rank coals. Coal samples no. 141 and 148 contained over $13 \%$ of these macerals. Medium-rank coal samples contained less than $6 \%$ of this component.

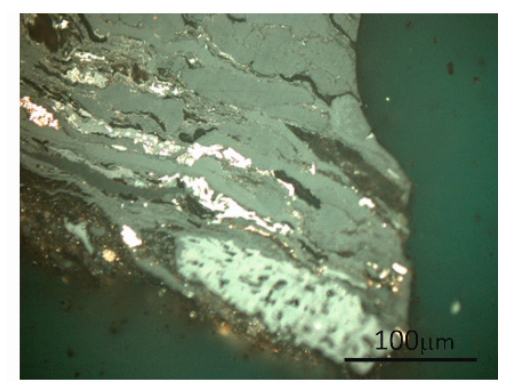

(a)

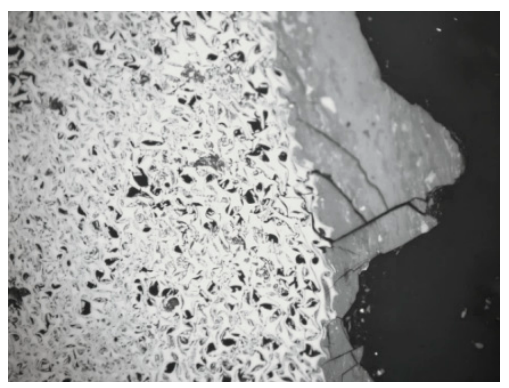

(d)

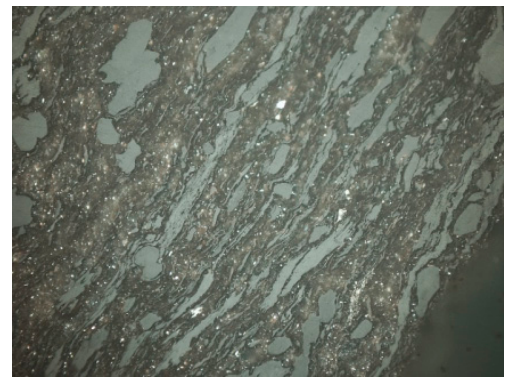

(b)

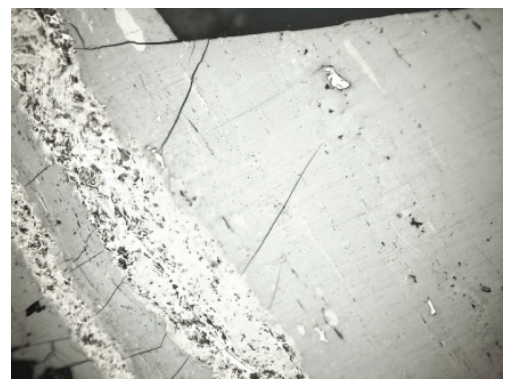

(e)

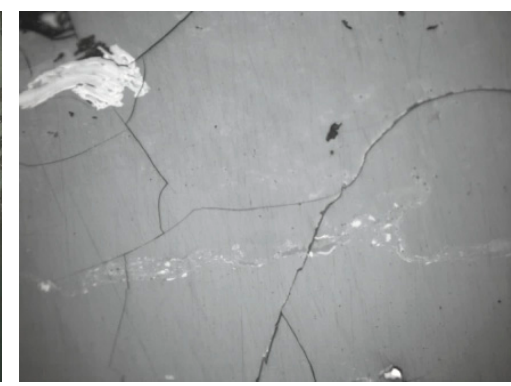

(c)

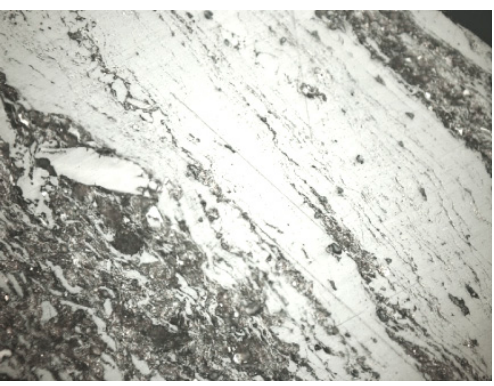

(f)

Figure 2. (a) Low-rank coal - a part of coal made of vitrinite, inertinite, and liptinite macerals, as well as smudges of mineral matter; (b) low-rank coal—carbominerite part-mineral matter (loam) overgrowing coal parts made of vitrinite maceral group; (c) medium-rank coal—cracked vitrinite—colotelinite and a part of a inertinite macerals; (d) medium-rank coal—a large inertinite (fusinite) part and a smaller part made of vitrinite; (e) high-rank coal—a lightly cracked part made of vitrinite with an inertinite lamella; and (f) high-rank coal—vitrinite and minerals; reflected light, immersion.

Another petrographic parameter distinguishing coals with various metamorphism degree is the mineral matter content. Young coal deposits usually contain much higher levels of mineral matter compared with mature deposits (Table 1, Figure 4). Medium- and high-rank coals contain no more than $4 \%$ of minerals and reach almost $15 \%$ in coal with low $R_{0}$ (cf. 97, Figure $2 b$ ). 


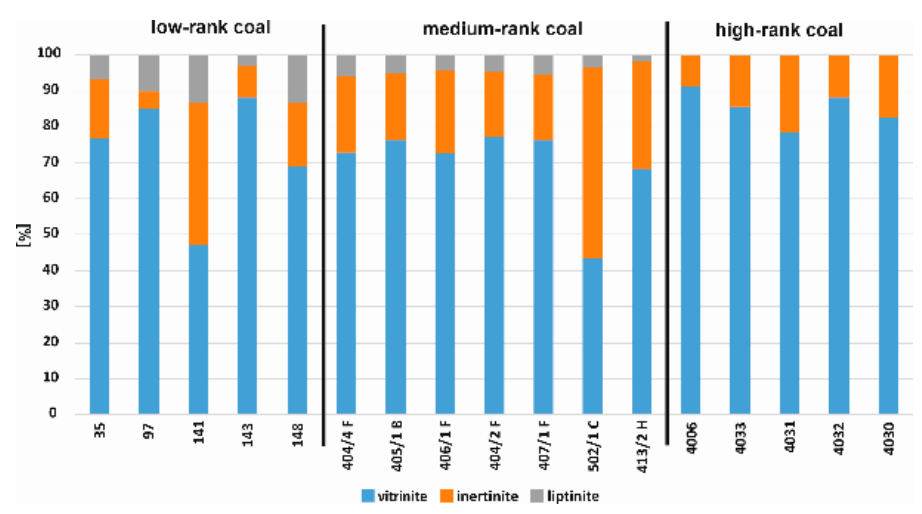

Figure 3. Share of main maceral groups in samples of various metamorphism degree (recalculated to mineral matter-free (mmf)).

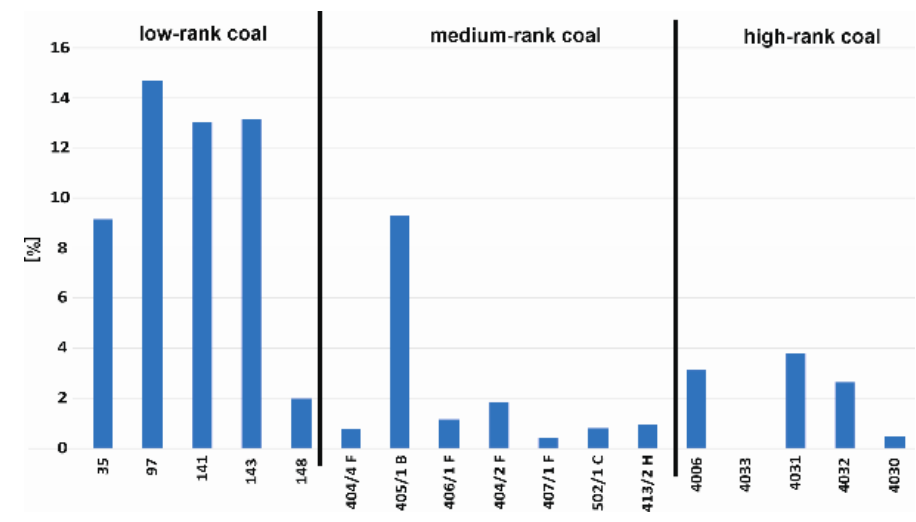

Figure 4. Mineral matter content in samples of various metamorphism degrees.

\subsection{Results of Micro-Hardness Tests}

Micro-hardness parameters change with the metamorphism degree and with the structural and textural characteristics of coal. This relationship, described by many authors [52-56], can also be seen in the coals from the USCB area described in this work.

The results of micro-hardness tests led to a conclusion that the analysed samples belong to three "ranges" (Table 1). These ranges overlap with the division of samples according to their metamorphism degree. Low-rank coal samples are characterised by the highest micro-hardness of vitrinite (average $H_{v}$ =69.25; Figure 5, Table 1). The Vickers cone leaves a relatively small mark on the samples, which means that low-rank coal does not show a tendency to crack under the load of $0.5 \mathrm{~N}$. The samples are only lightly deformed and show some plastic behaviour (Figure 6a), while displaying high values of the micro-hardness parameter $\left(H_{v}\right)$. Medium-rank coal samples show a significant decrease of micro-hardness (average $H_{v}=58.5$; Figure 5, Table 1), and the pressure of the Vickers cone leaves noticeable marks after the measurement. All analysed samples showed extensive cracks from the tops of the impressions, and sometimes detached parts of the material (Figure 6b). The damage visible on the coal surface indicates that this material is easily crushed. High-rank coal samples are characterised by a further decrease of micro-hardness (average $H_{v}=55.9$; Figure 5, Table 1 ). Clear marks left by the Vickers pyramid are visible on the vitrinite surface after the micro-hardness test, but cracks around the impression are not as spectacular as in the case of medium-rank coal samples. Cracks and detached material parts are still visible, but a larger part of the deformed coal is concentrated within the impression and around it (Figure 6c). 


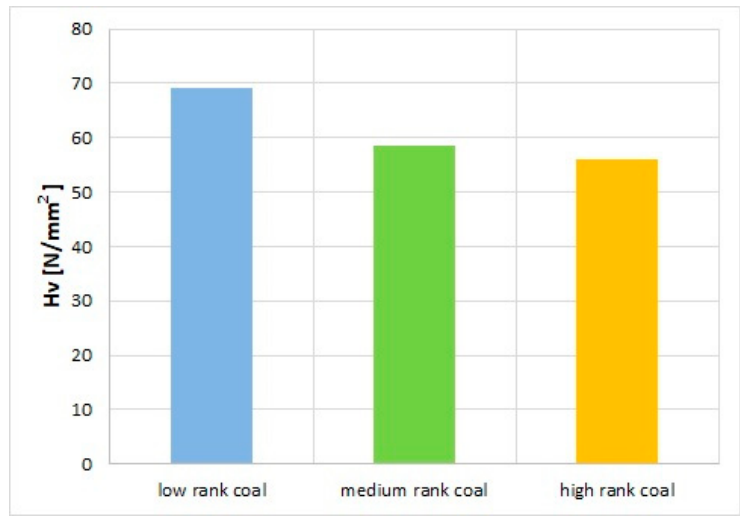

Figure 5. Average micro-hardness values for samples with different metamorphism degree.

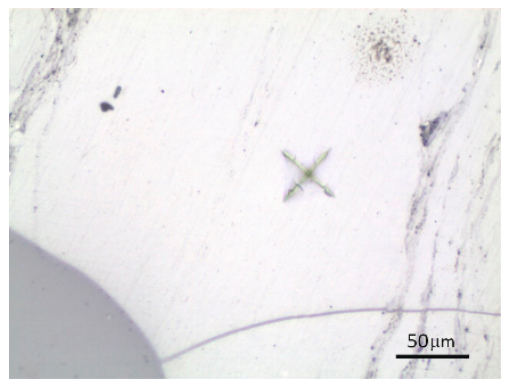

(a)

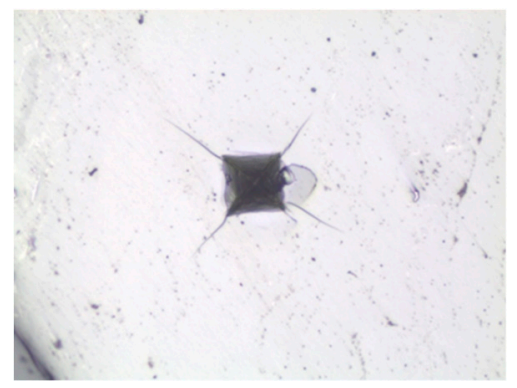

(b)

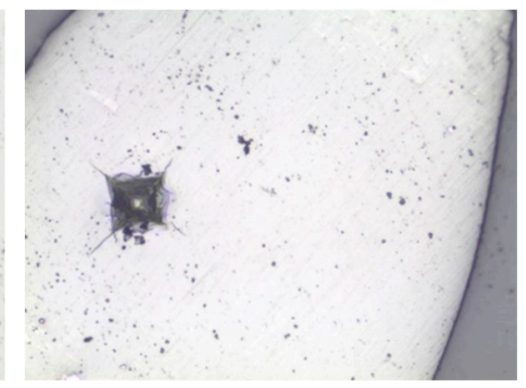

(c)

Figure 6. Photographs after the microhardness analysis, showing the nature of cracks and other damage caused by the Vickers indenter being pressed into the analysed material. (a) $R_{0}=0.8 \%$; (b) $R_{0}=1.1 \%$; (c) $R_{0}=2 \%$. Reflected light.

\subsection{Sorption Test Results}

Figure 7 presents example changes of the amount of adsorbed methane over time, determined under the pressure of 1 bar at $20^{\circ} \mathrm{C}$. Normalisation of the obtained data to the $[0,1]$ range enables determination of the effective diffusion coefficient $D_{e}$ of methane in coal, according to Formula [4]. On the basis of methane sorption isotherms (Figure 8) and of the Langmuir Equation [3], the sorption capacity $a_{1}$ and the maximum sorption capacity $a_{m}$ values were determined. The results are presented in Table 1.

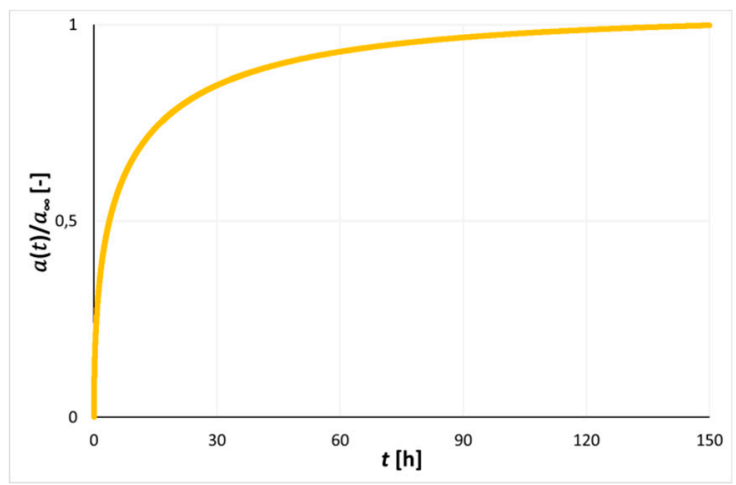

Figure 7. Methane sorption kinetics after normalisation of the adsorbed amount (high-rank coal 4030). 


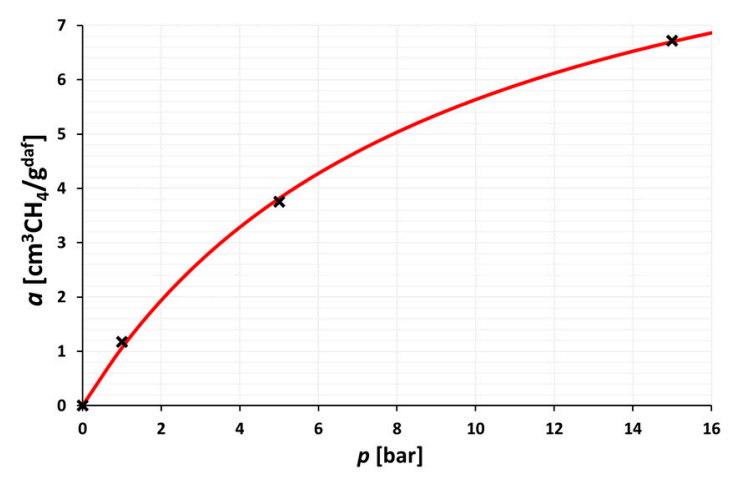

Figure 8. Methane sorption isotherm resulting from the fitting of the Langmuir model (low-rank coal 143).

Highly metamorphized coals are excellent sorbents of methane. Sorption capacity $a_{1}$ varies between 2.8 and $4.3 \mathrm{~cm}^{3} \mathrm{CH}_{4} / \mathrm{g}$. The maximum sorption capacity $a_{m}$ of these coals varies between approximately 23.5 and approximately $26 \mathrm{~cm}^{3} \mathrm{CH}_{4} / \mathrm{g}$. In the case of low-rank coals, the sorption capacity $a_{1}$ does not exceed $2.5 \mathrm{~cm}^{3} \mathrm{CH}_{4} / \mathrm{g}$, while the maximum sorption of methane for low- and medium-rank coals is not higher than slightly above $19 \mathrm{~cm}^{3} \mathrm{CH}_{4} / \mathrm{g}$. At a constant temperature, an increase in methane sorption capacity was observed from lower rank coals towards those with a higher degree of metamorphism. According to [12], the minimum of sorption capacity value falls on the reflectance $R_{0}$ around 1.0, which corresponds to the lowest volume of micropores in dry coals (see Table 1).

In the case of high-rank coal samples, the kinetics included approximately $150 \mathrm{~h}$ of the saturation process (Figure 7), while in the case of low- and medium-rank coal samples, methane sorption takes less than $20 \mathrm{~h}$. The variation ranges of the effective diffusion coefficient $D_{e}$ in the group of highly metamorphized coals correspond to the range of $1.13 \times 10^{-10} \mathrm{~cm}^{2} / \mathrm{s}$ to $3.46 \times 10^{-10} \mathrm{~cm}^{2} / \mathrm{s}$. In the group of medium-rank coals, the value of effective diffusion coefficient $D_{e}$ varies between $4.00 \times 10^{-10} \mathrm{~cm}^{2} / \mathrm{s}$ and $9.77 \times 10^{-10} \mathrm{~cm}^{2} / \mathrm{s}$, while in the group of low-rank coals, it varies between $4.18 \times 10^{-10} \mathrm{~cm}^{2} / \mathrm{s}$ and $8.90 \times 10^{-10} \mathrm{~cm}^{2} / \mathrm{s}$. At $20^{\circ} \mathrm{C}$, medium-rank coals show the best ability to transport methane (Table 1 ). Undoubtedly, the degree of metamorphism significantly influences the development of the porous structure of coal, which affects the kinetics of sorption processes $[8,13]$.

\section{Discussion}

The discussion part includes a statistical analysis of the results obtained from the performed laboratory measurements. The ability to estimate sorption parameters $a_{1}, a_{m}$, and $D_{e}$ using other petrophysical parameters was analysed.

\subsection{The Search for Estimation Models}

The first stage included analysis of the presence of correlations between the $a_{m}, a_{1}$, or $D_{e}$ variables and other petrophysical parameters. The presence of both linear and non-linear correlations was estimated, determining Pearson's linear correlation coefficients and Spearman's rank correlation. The statistical significance level of $p=0.05$ was assumed. The results of correlation analyses are included in Tables 2 and 3.

The performed analysis shows that the maximum sorption capacity $a_{m}$ displays linear relationships with petrophysical parameters. These relationships are statistically significant for the $V^{d a f}, R_{0}, L^{m m f}, M$, $H_{v}, I^{m m}$, and $V_{p}$ variables. The $a_{m}$ and $E_{I T}$ values show a slightly non-linear relationship (see Table 3 ). Linear relationships were obtained for the sorption capacity at the specified pressure $\left(a_{1}\right)$ for $E_{I T}$ and $H_{v}$ and non-linear relationships for $V^{d a f}, R_{0}$, and $L^{m m f}$. In the case of the effective diffusion coefficient $D_{e}$, linear relationships were shown for $R_{0}, I^{m m f}$, and $\left(V_{t}+L\right)^{m m f}$ variables, while non-linear relationships applied to parameters such as $V^{\text {daf }}, V t^{m m f}, L^{m m f}, I^{m m f}$, and $V p$ (Tables 2 and 3 ). 
Table 2. Pearson correlation coefficient for correlation between sorption and petrophysical parameters of the tested coals. Statistically significant correlations (for $p<$ 0.05 ) are presented in bold type.

\begin{tabular}{|c|c|c|c|c|c|c|c|c|c|c|c|c|c|c|}
\hline & $\rho_{r}$ & $\rho_{p}$ & $V^{\text {daf }}$ & $A^{a}$ & $R_{0}$ & $V t^{m m f}$ & $I^{m m f}$ & $L^{m m f}$ & $\left(V_{t}+L\right)^{m m f}$ & $M$ & $E_{I T}$ & $H_{v}$ & $\varepsilon$ & $V_{p}$ \\
\hline$a_{m}\left[\mathrm{~cm}^{3} / \mathrm{g}\right]$ & 0.015 & -0.224 & -0.822 & 0.043 & 0.904 & 0.394 & -0.201 & -0.668 & 0.201 & -0.538 & -0.531 & -0.560 & 0.693 & 0.705 \\
\hline$a_{1}\left[\mathrm{~cm}^{3} / \mathrm{g}\right]$ & -0.232 & -0.398 & -0.797 & -0.108 & 0.721 & 0.181 & 0.014 & -0.591 & -0.014 & -0.598 & -0.649 & -0.809 & 0.461 & 0.501 \\
\hline$D_{e}\left[\mathrm{~cm}^{2} / \mathrm{s}\right]$ & -0.075 & 0.142 & 0.450 & 0.094 & -0.703 & -0.663 & 0.531 & 0.616 & -0.531 & 0.153 & 0.158 & 0.239 & -0.639 & -0.642 \\
\hline
\end{tabular}

Table 3. Spearman's rank correlation between sorption and petrophysical parameters of the studied coal samples. Statistically significant correlations (for $p<0.05$ ) are presented in bold type.

\begin{tabular}{|c|c|c|c|c|c|c|c|c|c|c|c|c|c|c|}
\hline & $\rho_{r}$ & $\rho_{p}$ & $V^{d a f}$ & $A^{a}$ & $R_{0}$ & $V t^{m m f}$ & $I^{m m f}$ & $L^{m m f}$ & $\left(V_{t}+L\right)^{m m f}$ & $M$ & $E_{I T}$ & $H_{v}$ & $\varepsilon$ & $V_{p}$ \\
\hline$a_{m}\left[\mathrm{~cm}^{3} / \mathrm{g}\right]$ & 0.136 & -0.154 & -0.750 & 0.200 & 0.729 & 0.382 & -0.107 & -0.687 & 0.107 & -0.361 & -0.550 & -0.543 & 0.543 & 0.543 \\
\hline$a_{1}\left[\mathrm{~cm}^{3} / \mathrm{g}\right]$ & -0.139 & -0.425 & -0.821 & 0.004 & 0.804 & 0.164 & 0.214 & -0.658 & -0.214 & -0.429 & -0.532 & -0.789 & 0.425 & 0.454 \\
\hline$D_{e}\left[\mathrm{~cm}^{2} / \mathrm{s}\right]$ & -0.290 & -0.120 & 0.629 & -0.101 & -0.593 & -0.697 & 0.508 & 0.735 & -0.508 & 0.014 & 0.136 & 0.290 & -0.710 & -0.701 \\
\hline
\end{tabular}


The linear relationships between sorption parameters and the metamorphism degree characterised by reflectance $R_{0}$ may be approximated:

$$
\begin{gathered}
a_{m}=8.24+8.3 R_{0} \\
a_{1}=1.24+1.30 R_{0} \\
D_{e}^{*}=0.94-0.37 R_{0}
\end{gathered}
$$

where $D_{e}^{*}=D_{e} \times 10^{9}$

Owing to the confirmation of the existence of linear and non-linear relationships between sorption and petrographic parameters, it is possible to create good quality models of sorption parameters using regression methods.

\subsection{Use of Multiple Regression in the Development of Mathematical Models for Sorption Parameters}

Correlation results were used to create multiple regression models for the selected sorption parameters. The first group of models applies to additive, linear relationships between the dependent variable $a_{m}$ and the previously selected, independent variables. This model is presented using Equation (10).

$$
a_{m}=36.97+4.85 \cdot R_{0}-3.94 \cdot E_{I T}-0.42 \cdot M-0.1 \cdot I^{m m f}+0.27 \cdot A^{a}
$$

In the case of this model, all parameters are statistically significant for the assumed confidence interval. The determination coefficient $R^{2}$ explains the $94 \%$ of the $a_{m}$ value variability, and the average estimation error of this parameter is 1.425 , that is, approximately $7.5 \%$. A graphical comparison of the results of the maximum sorption capacity with the created regression model is presented in Figure 9. The regression model provides a good approximation of the sorption capacity $a_{m}$ and may estimate its values with adequate accuracy.

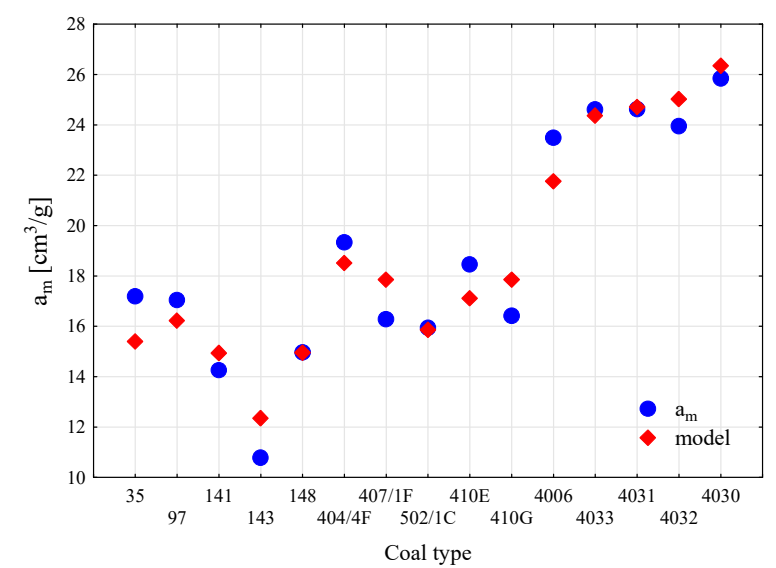

Figure 9. Value comparison between the maximum sorption capacity $a_{m}$ and the created regression model (Equation (10)).

A comparison of measurements with the linear model for sorption capacity under the set pressure $a_{1}$ is presented in the Equation (11), and its graphical comparison with the obtained results is presented in Figure 10.

$$
a_{1}=7.56-0.06 \cdot H_{v}-0.04 \cdot V^{d a f}
$$




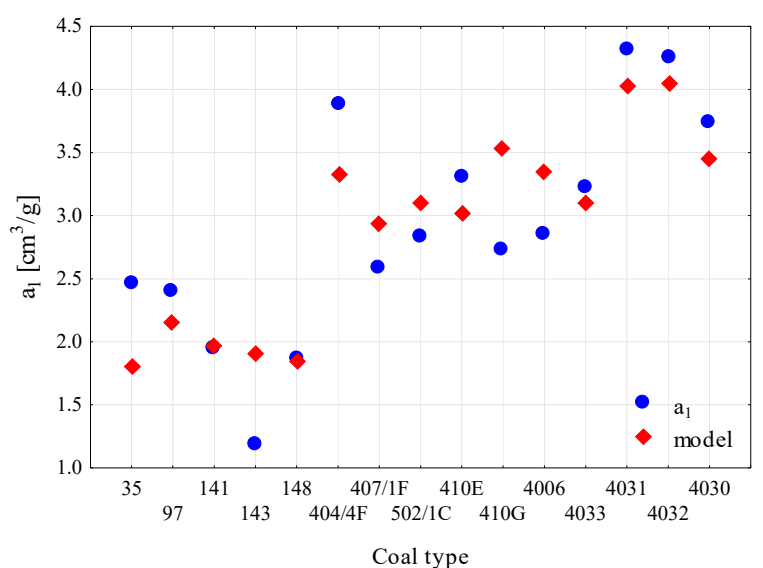

Figure 10. Value comparison between the sorption capacity under set pressure $a_{1}$ with the created regression model (Equation (11)).

This model is statistically significant; however, it has an estimation error of 0.48 , comprising $16 \%$ of the average level of the phenomenon. The quality of the model evaluated using the determination coefficient is 0.75 . The model quality is adequately high for the model to be used as an approximation of $a_{1}$ values.

In order to create a multiple regression model for the effective diffusion coefficient $D_{e}$, data were transformed by multiplying by $10^{9}$. This transformation did not influence the model accuracy and the percentage of the explained data variance. This model is presented using Equation (12).

$$
D_{e}^{*}=0.725-0.34 \cdot R_{0}+0.009 \cdot I^{m m f}
$$

A graphical comparison of the De diffusion coefficient results with the created regression model is presented in Figure 11. This model is statistically correct and explains $62 \%$ of data variability. The standard estimation error is 0.16 , or about $35 \%$ of the average value.

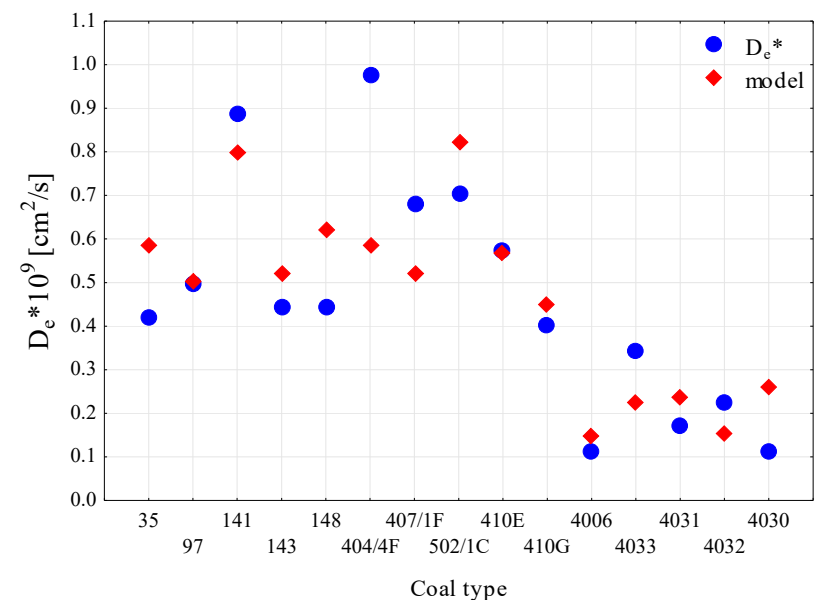

Figure 11. Value comparison between the effective diffusion coefficient $D e$ and the created regression model (Equation (12)).

A model taking into account non-linear relationships in MARSpline data was also created for the effective diffusion coefficient De. The obtained results are very similar to the results of multiple regression $\left(R^{2}=0.677\right.$, the estimation error was 0.151$)$. The model of a multi-layer perceptron (MLP)-type neuron network also did not show a significantly higher value of the explained data variability $\mathrm{R}^{2}$ : 0.67 and 0.72 for the best network architectures (MLP 2-8-1, MLP 2-10-1). 
4.3. Optimisation of the Method for Prediction of Sorption Properties of a Natural Coal Sorbent Based on Multiple Regression

Table 4 provides a summary of the results obtained using multiple regression in order to predict sorption properties of coal: $a_{m}, a_{1}$, and $D_{e}$. This summary includes the values of the determination coefficient $\mathrm{R}^{2}$ and Pearson's linear correlation coefficient $(\mathrm{R})$ for various configurations of parameters introduced into the model. Sets of petrophysical parameters resulting in models best fit to actual data are also presented, as well as a fit for independent variables $R_{0}$ and $V^{\text {daf }}$. This was intended to show whether the introduction of parameters often used interchangeably to the model in order to evaluate the metamorphism degree contributes to an improved predictive ability of the constructed model.

Table 4. Analysis of the fitting quality of various multiple regression models.

\begin{tabular}{cccc}
\hline Independent Variables & Dependent Variables & $\mathbf{R}^{\mathbf{2}}$ & $\mathbf{R}$ \\
\hline$R_{0}$ & & 0.520 & 0.721 \\
$R_{0}, M$ & $a_{1}$ & 0.593 & 0.770 \\
$R_{0}, V p$ & 0.562 & 0.750 \\
$R_{0}, H_{v}$ & 0.744 & 0.863 \\
$H_{v}, V^{\text {daf }}$ & & 0.754 & 0.868 \\
\hline$R_{0}$ & & 0.818 & 0.904 \\
$R_{0}, V^{\text {daf }}$ & & 0.821 & 0.906 \\
$R_{0}, M$ & 0.826 & 0.910 \\
$V^{\text {daf }}, V p$ & & 0.705 & 0.839 \\
$V^{\text {daf }}, H_{v}$ & 0.678 & 0.823 \\
$R_{0}, E_{I T}, M, I, A$ & & 0.937 & 0.968 \\
\hline$R_{0}$ & & 0.494 & 0.703 \\
$R_{0}, V^{d a f}$ & & 0.619 & 0.786 \\
$R_{0}, V t$ & & 0.672 & 0.820 \\
$R_{0}, I$ & $D_{e}$ & 0.677 & 0.823 \\
$R_{0}, V p$ & & 0.502 & 0.708 \\
$V t, \varepsilon$ & & 0.557 & 0.746 \\
$I, \varepsilon$ & & 0.508 & 0.713 \\
\hline
\end{tabular}

The increased number of independent variables had a positive influence on the quality of the developed model and the ability to estimate sorption parameters. Supplementing the $a_{1}\left(R_{0}\right)$ model with one adequate petrophysical parameter resulted in a noticeable improvement of the sorption capacity estimation under the set pressure $\left(a_{1}\right)$. The best results were obtained on the basis of the $\left(R_{0}, H_{v}\right)$ parameter pair, or alternatively using the $\left(V^{d a f}, H_{v}\right)$ pair. As a result, the multiple regression model based on the parameter determining the metamorphism degree of the sorbent and its Vickers micro-hardness enables the sorption capacity $a_{1}$ to be estimated in $86 \%$ of cases. The explanatory variables $R_{0}$ and $V^{\text {daf }}$ may thus be alternatively introduced to the model, depending on the decision of the researcher regarding parameter selection or on how easy it is to determine. As the $R_{0}$ and $V^{\text {daf }}$ parameters are intended to indicate the same coal property (metamorphism degree), implementation of both to the same model is redundant.

The performed statistical analysis showed that the $R_{0}$ parameter adequately $\left(R=0.9, R^{2}=0.82\right)$ enables correct conclusions related to the maximum coal capacity towards the adsorbed methane $\left(a_{m}\right)$. Statistical methods decisively showed that the introduction of five different petrophysical parameters clearly influences the quality of the developed prediction model (almost 97\% variability of data explained by the model).

In the case of kinetic aspects, it was shown that $R_{0}$ as the sole parameter used in the conventional regression model enables approximation of the value of effective diffusion coefficient $D_{e}$ on the level of $49 \%$ variability of the original variable. Introduction of an additional petrophysical parameter explains $62 \%$ of the variability of $D_{e}$. In the case of the kinetic parameter, the petrographic structure of coal and the 
content of vitrinite and inertinite maceral groups were particularly important. However, the standard estimation error $(>30 \%)$ is very high, and the model accuracy may not be adequate for practical purposes. The development of an MLP-type neuron network $\left(R^{2}=0.67\right)$ and MARSpline $\left(R^{2}=0.72\right)$ did not improve the model quality significantly.

\section{Conclusions}

The presented studies led to the conclusion that the use of multiple regression improves the quality of prediction of the sorption capacity of coal $a_{1}$ and $a_{m}$, as well as of the kinetic parameter $D_{e}$. It was shown that the $a_{1}$ parameter may be modelled on the basis of the $R_{0}$ and $H_{v}$ parameters, while the De parameter may be modelled on the basis of $R_{0}$ and $W_{t}$ or $R_{0}$ and $I^{m m f}$ pairs. Vickers micro-hardness, which may be considered a measure of the specific structure and behaviour of this natural sorbent, is a very important parameter in the estimation of the usefulness of coal as a methane sorbent. In some cases, the $V^{\text {daf }}$ and $R_{0}$ parameters may be used interchangeably, depending on measurement capacity, for example, in order to determine the value of $a_{1}$. It should be noted that the introduction of both of these parameters into the multiple regression model is redundant.

Thanks to the statistical method of multiple analysis, it is possible to develop a computational model enabling prediction of optimal sorption properties of coal and their subsequent use in specific applications. Contrary to the classical regression method, the multiple regression model includes at least two independent variables (here, petrophysical parameters), synergising with the specified sorption property - capacity or kinetics. The model may be optimised by selecting the adequate number of the best petrophysical parameters. An advantage of optimisation lies in the potential reduction of the number of parameters introduced into the model, and their introduction enables satisfactory evaluation of the sorption properties of coal (minimisation).

Author Contributions: Conceptualization, K.G., B.D., and M.M.; methodology, K.G., B.D., M.C., and M.M.; formal analysis, K.G., B.D., M.C., and M.M.; investigation, K.G., B.D., M.C., and M.M.; resources, K.G. and B.D.; writing—original draft preparation, K.G., B.D., and M.C.; writing—review and editing, B.D. and M.M; supervision, M.M. All authors have read and agreed to the published version of the manuscript.

Funding: This research received no external funding.

Acknowledgments: The presented work was supported through a statutory research fund by the Polish Academy of Sciences and by the AGH-University of Science and Technology, Faculty of Geology, Geophysics, and Environmental Protection. We would like to thank Alena Kozusnikova and Lucie Nemcova of the Institute of Geonics in Ostrava for their help in micro-hardness and reflectance analyses.

Conflicts of Interest: The authors declare no conflict of interest.

\section{References}

1. Wojtacha-Rychter, K.; Smoliński, A. Sorption characteristic of coal as regards of gas mixtures emitted in the process of the self-heating of coal. In Proceedings of the E3S Web of Conferences 19, 01010. International Conference Energy, Environment and Material Systems (EEMS 2017), Polanica Zdroj, Poland, 13-15 September 2017.

2. Pan, Z.; Ye, J.; Zhou, F.; Tan, Y.; Connell, L.D.; Fan, J. CO2 storage in coal to enhance coalbed methane recovery: A review of field experiments in China. Int. Geol. Rev. 2017, 60, 754-776. [CrossRef]

3. Cuéllar-Franca, R.M.; Azapagic, A. Carbon capture, storage and utilisation technologies: A critical analysis and comparison of their life cycle environmental impacts. J. CO2 Util. 2015, 9, 82-102. [CrossRef]

4. Radosz, M.; Hu, X.; Krutkramelis, K.; Shen, Y. Flue-Gas Carbon Capture on Carbonaceous Sorbents: Toward a Low-Cost Multifunctional Carbon Filter for “Green” Energy Producers. Ind. Eng. Chem. Res. 2008, 47, 3783-3794. [CrossRef]

5. Skoczylas, N.; Wierzbicki, M.; Kudasik, M. A Simple Method for Measuring Basic Parameters of the Coal-Methane System under Mining Conditions. J. Min. Sci. 2018, 54, 522-533. [CrossRef]

6. Dutka, B. $\mathrm{CO}_{2}$ and $\mathrm{CH}_{4}$ sorption properties of granular coal briquettes under in situ states. Fuel 2019, 247, 228-236. [CrossRef] 
7. Pajdak, A.; Kudasik, M.; Skoczylas, N.; Wierzbicki, M.; Teixeira Palla Braga, L. Studies on the competitive sorption of CO2 and CH4 on hard coal. Int. J. Greenh. Gas Control 2019, 90, 102789. [CrossRef]

8. Li, D.; Liu, Q.; Weniger, P.; Gensterblum, Y.; Busch, A.; Krooss, B.M. High-pressure sorption isotherms and sorption kinetics of $\mathrm{CH} 4$ and $\mathrm{CO} 2$ on coals. Fuel 2010, 89, 569-580. [CrossRef]

9. Godyń, K.; Dutka, B. The impact of the degree of coalification on the sorption capacity of coals from the Zofiówka Monocline. Arch. Min. Sci. 2018, 63, 727-746.

10. Skoczylas, N.; Topolnicki, J. The coal-gas system-the effective diffusion coefficient. Int. J. Oil Gas Coal Technol. 2016, 12, 412-424. [CrossRef]

11. Kudasik, M.; Skoczylas, N.; Pajdak, A. The repeatability of sorption processes occurring in the coal-methane system during multiple measurement series. Energies 2017, 10, 661. [CrossRef]

12. Levy, J.H.; Day, S.J.; Killingley, J.S. Methane capacities of Bowen Basin coals related to coal properties. Fuel 1997, 76, 813-819. [CrossRef]

13. Ceglarska-Stefańska, G.; Brzóska, K. The effect of coal metamorphism on methane desorption. Fuel 1998, 77, 645-648. [CrossRef]

14. Laxminarayana, C.; Crosdale, P. Role of coal type and rank on methane sorption characteristics of Bowen Basin, Australia coals. Int. J. Coal Geol. 1999, 40, 309-325. [CrossRef]

15. Prinz, D.; Pyckhout-Hintzen, W.; Littke, R. Development of the meso- and macroporous structure of coals with rank as analyzed with small angle neutron scattering and adsorption experiments. Fuel 2004, 83, 547-556. [CrossRef]

16. Dutta, P.; Bhowmik, S.; Das, S. Methane and carbon dioxide sorption on a set of coals from India. Int. J. Coal Geol. 2011, 85, 289-299. [CrossRef]

17. Olajossy, A. The influences of the rank of coal on methane sorption capacity in coals. Arch. Min. Sci. 2014, 59, 509-516.

18. Nie, B.; Liu, X.; Yuan, S.; Ge, B.; Jia, W.; Wang, C.; Chen, X. Sorption charateristics of methane among various rank coals: Impact of moisture. Adsorption 2016, 22, 315-325. [CrossRef]

19. Dutka, B.; Godyń, K. Predicting variability of methane pressure with depth of coal seam. Przem. Chem. 2018, 97, 1344-1348.

20. Pini, R.; Ottiger, S.; Burlini, L.; Storti, G.; Mazzotti, M. Sorption of carbon dioxide, methane and nitrogen in dry coals at high pressure and moderate temperature. Int. J. Greenh. Gas Control 2010, 4, 90-101. [CrossRef]

21. Feng, Q.; Zhang, J.; Zhang, X.; Shu, C.; Wen, S.; Wang, S.; Li, J. The use of alternating conditional expectation to predict methane sorption capacity on coal. Int. J. Coal Geol. 2014, 121, 137-147. [CrossRef]

22. Yao, Y.; Liu, D.; Huang, W. Influences of igneous intrusions on coal rank, coal quality and adsorption capacity in Hongyang, Handan and Huaibei coalfields, North China. Int. J. Coal Geol. 2011, 88, 135-146. [CrossRef]

23. Godyń, K. Structurally altered hard coal in the areas of tectonic disturbances-an initial attempt at classification. Arch. Min. Sci. 2016, 61, 677-694. [CrossRef]

24. Wang, Y.; Liu, D.; Cai, Y.; Li, X. Variation of Petrophysical Properties and Adsorption Capacity in Different Rank Coals: An Experimental Study of Coals from the Junggar, Ordos and Qinshui Basins in China. Energies 2019, 12, 986. [CrossRef]

25. Weniger, P.; Franců, J.; Hemza, P.; Krooss, B.M. Investigations on the methane and carbon dioxide sorption capacity of coals from the SW Upper Silesian Coal Basin, Czech Republic. Int. J. Coal Geol. 2012, 93, 23-39. [CrossRef]

26. Godyń, K.; Młynarczuk, M.; Skiba, M.; Dutka, B.; Králová, L. Studies into the relationship between the technical, petrographic, gas and strength parameters of coal from seams located in the Upper Silesian Coal Basin. Int. Multidiscip. Sci. GeoConf. SGEM 2019, 19, 553-559.

27. Dembowski, Z. General Information on the Upper Silesian Basin. Prace Inst. Geol. 1972, 61, 9-22.

28. Jureczka, J. Nowe dane o charakterystyce litostratygraficznej kontaktu serii paralicznej i górnoślaskiej serii piaskowcowej karbonu zachodniej części Górnosląskiego Zagłebia Węgłowego. In XI Sympozjum Geologia formacji węglonośnych Polski; AGH Kraków: Kraków, Poland, 1988; pp. 41-66.

29. Kotas, A.; Buła, Z.; Jureczka, J. Problematyka podziału litostratygraficznego Górnosląskiej serii piaskowcowej karbonu GZW w świetle zasad kodeksu stratygraficznego. In XI Sympozjum Geologia formacji węglonośnych Polski; AGH Kraków: Kraków, Poland, 1988; pp. 55-61.

30. Sivek, M.; Dopita, M.; Krůl, M.; Čáslavský, M.; Jirásek, J. Atlas of Chemical-Technological Properties of Coals in the Czech Part of the Upper Silesian Basin; Vysoká Škola Báňská-Technical University of Ostrava: Ostrava, Czech Republic, 2003; p. 31. 
31. Hýlová, L.; Jureczka, J.; Jirásek, J.; Sivek, M.; Hotárková, J. The Petřkovice Member (Ostrava Formation, Mississippian) of the Upper Silesian Basin (Czech Republic and Poland). Int. J. Coal Geol. 2013, 106, 11-24. [CrossRef]

32. Jirásek, J.; Opluštil, S.; Sivek, M.; Schmitz, M.D.; Abels, H.A. Astronomical forcing of Carboniferous paralic sedimentary cycles in the Upper Silesian Basin, Czech Republic (Serpukhovian, latest Mississippian): New radiometric ages afford an astronomical age model for European biozonations and substages. Earth-Sci. Rev. 2018, 177, 715-741. [CrossRef]

33. ISO 562:2010: Hard Coal and Coke-Determination of Volatile Matter; IOS: Geneva, Switzerland, 15 June 2010.

34. ISO 1171:2010: Solid Mineral Fuels-Determination of Ash; IOS: Geneva, Switzerland, 30 November 2010.

35. ISO 7404-2:2009: Methods for the Petrographic Analysis of Coals-Part 2: Methods of preparing Coal Samples; IOS: Geneva, Switzerland, 1 October 2009.

36. ISO 7404-3:2009: Methods for the Petrographic Analysis of Coals-Part 3: Method of Determining Maceral Group Composition; IOS: eneva, Switzerland, 1 October 2009.

37. Bodziony, J.; Gabzdyl, W.; Ratajczak, T. Evaluation of effect of a subjective factor on the results of stereological analysis of coal. Arch. Min. Sci. 1986, 31, 689-702.

38. Wang, H.; Lei, M.; Chen, Y.; Li, M.; Zou, L. Intelligent Identification of Maceral Components of Coal Based on Image Segmentation and Classification. Appl. Sci. 2019, 9, 3245. [CrossRef]

39. Młynarczuk, M.; Skiba, M. The application of artificial intelligence for the identification of the maceral groups and mineral components of coal. Comput. Geosci. 2017, 103, 133-141. [CrossRef]

40. Skiba, M.; Młynarczuk, M. Identification of macerals of the inertinite group using neural classifiers, based on selected textural features. Arch. Min. Sci. 2018, 63, 827-837.

41. ISO 7404-5:2009: Methods for the Petrographic Analysis of Coals-Part 5: Method of Determining Microscopically the Reflectance of Vitrinite; IOS: Geneva, Switzerland, 1 October 2009.

42. Klika, Z.; Serenčíšová, J.; Kožušníková, A.; Kolomazník, I.; Študentová, S.; Vontorová, J. Multivariate statistical assessment of coal properties. Fuel Process. Technol. 2014, 128, 119-127. [CrossRef]

43. Langmuir, I. The adsorption of gases on plane surfaces of glass, mica and Platinum. J. Am. Chem. Soc. 1918, 40, 1361-1403. [CrossRef]

44. Crank, J. The Mathematics of Diffusion, 2nd ed.; Oxford Science Publications: Oxford, UK, 1975.

45. Timofejew, D.P. Adsorptionskinetik; VEB: Lipsk, Germany, 1967.

46. Oliver, W.C.; Pharr, G.M. An improved technique for determining hardness and elastic modulus using load and displacement sensing indentation experiments. J. Mater. Res. 1992, 7, 1564-1583. [CrossRef]

47. Kožušníková, A. Determination of microhardness and elastic modulus of coal components by using indentation method. Geolines 2009, 22, 40-43.

48. Borradaile, G.J. Statistics of Earth Science Data; Springer: Berlin/Heidelberg, Germany, 2003.

49. Chuchro, M.; Danek, M. Selection of optimal gridded dataset for application in Polish Sudetes Mountains. IOP Conf. Ser. Earth Environ. Sci. 2018, 012120, 1-8.

50. Zhang, W.; Goh, A.T.C. Multivariate adaptive regression splines and neural network models for prediction of pile drivability. Geosci. Front. 2016, 7, 45-52. [CrossRef]

51. UNECE. International Classification of In-Seam Coals; ECE UN: Geneva, Switzerland; UN: New York, NY, USA, 1998.

52. Stach, E.; Mackowsky, M.-T.; Teichmuller, M.; Taylor, G.H.; Chandra, D.; Teichmuller, R. Stach's Textbook of Coal Petrology; Gebruder Borntraeger: Berlin/Stuttgart, Germany, 1982.

53. Mukherjee, A.K.; Alam, M.M.; Ghose, S. Microhardness Characteristics of Indian Coal and Lignite. Fuel 1989, 68, 670-674. [CrossRef]

54. Van Krevelen, D.W. Coal-Typology-Physics-Chemistry-Constitution; Elsevier: Amsterdam, The Netherlands, 1993.

55. Hower, J.C.; Trinkle, E.J.; Raione, R.P. Vickers microhardness of telovitrinite and pseudovitrinite from high volatile bituminous Kentucky coals. Int. J. Coal Geol. 2008, 75, 76-80. [CrossRef]

56. Godyń, K.; Kožušníková, A. Microhardness of Coal from Near-Fault Zones in Coal Seams Threatened with Gas-Geodynamic Phenomena, Upper Silesian Coal Basin, Poland. Energies 2019, 12, 1756.

(C) 2020 by the authors. Licensee MDPI, Basel, Switzerland. This article is an open access article distributed under the terms and conditions of the Creative Commons Attribution (CC BY) license (http://creativecommons.org/licenses/by/4.0/). 